\title{
Fim de vida e recusa de tratamento médico no direito Português
}

\author{
End of life and refusal of medical treatment in the portuguese legal system
}

Fin de la vida y la denegación de tratamiento médico en la legislación portuguesa

Geraldo Rocha Ribeiro ${ }^{1}$

\begin{abstract}
RESUMO: Pretendemos, com o presente artigo, fazer um enquadramento jurídico breve sobre a figura da directiva antecipada de vontade e sobre o problema das decisões de fim de vida, distinguindo as situações de recusa de tratamento das situações tipificadas de crime de homicídio a pedido da vítima (eutanásia). A análise será feita exclusivamente à luz do direito português, dando particular atenção à Lei n. 0 25/2012 que aprovou o regime das directivas antecipadas de vontade. Os nossos propósitos são os de deslindar um critério jurídico que distinga entre o exercício lícito e ilícito da autodeterminação e os de precisar o grau de vinculação de um directiva antecipada de vontade num momento tão melindroso da vida do seu outorgante.
\end{abstract}

Palavra-chave: Recusa de tratamento. Vontades antecipadas. Eutanásia.

ABSTRACT: With this article I intend to give a brief introduction to the Portuguese's legal framework on advance directive (or living wills) and end of life decisions. I expect to distinguish the situations of lawfully decisions of treatment refusal from the situations typified as crime of euthanasia. The analysis will be done exclusively in the Portuguese law, with particular attention to Law No. 25/2012 that approved the advance directives. Our purpose is to disentangle the legal criteria of lawful and unlawful exercise of selfdetermination and to specify the binding degree of an advance directive in a delicate moment for the grantor of the living will.

Keywords: Refusal of treatment. Living wills. Euthanasia.

RESUMEN: Tenemos la intención con este artículo, hacer una breve marco legal sobre la figura de la directiva anticipada voluntad y en el problema de la final de la vida, distinguiendo como a la negativa de las situaciones de tratamiento tipificado el delito de homicidio a petición de la víctima (eutanasia). El análisis se realiza exclusivamente a la luz de la legislación portuguesa, con especial atención a la Ley № 25/2012, que aprobó el régimen de directivas anticipadas voluntad. Nuestros propósitos son de desenredar los criterios legales para distinguir entre el ejercicio legal e ilegal de la libre determinación y para especificar el grado de unión de una directiva anticipada será en la vida, tales delicado de su otorgante.

Palabras-Ilave: Rechazo del tratamiento. Voluntades anticipadas. Eutanasia

\footnotetext{
${ }_{1}$ Assistente Convidado da Faculdade de Direito da Universidade de Coimbra, Membro do Centro de Direito Biomédico da Faculdade de Direito da Universidade de Coimbra, Portugal, rrgeraldo@me.com
} 


\section{Introdução}

A consagração legal expressa e respectivo enquadramento jurídico das figuras das directivas antecipadas de vontade (quer os testamentos vitais, quer as procurações para cuidados de saúde) foi feita em Portugal através da Lei n.. 25/2012 e aprovação do regulamento que regula Registo Nacional do Testamento Vital pela Portaria n.ำ 96/2014. Antecedendo a aprovação da Lei e o modelo por ela consagrado existiu um anteprojecto que não foi bem-sucedido pelas dúvidas que suscitava sobre os limites da autodeterminação e eutanásia ${ }^{2}$. Parte dessas criticas foram corporizadas no parecer da Comissão para as Ciências e Vida ${ }^{3}$. Não nos vamos ater muito mais à evolução histórica e política que antecedeu à discussão do actual regime legal, contudo não podemos deixar de apontar que entre 0 anteprojecto e a solução consagrada não existem grandes divergências no que toca ao grau de eficácia e vinculatividade das directivas antecipadas.

Mesmo antes da entrada em vigor da lei de 2012, existiam já autores que defendiam a validade e eficácia das directivas integrando-as como manifestação do exercício do direito ao livre desenvolvimento da personalidade (artigo 70.․, n.. 1 do Código Civil) e das regras sobre o consentimento presumido (artigo 340., n. -3 do Código Civil), abrindo caminho para o reconhecimento dos testamentos vitais e procurações antecipadas. Estas soluções com origem no direito privado estavam alinhadas com as próprias disposições penais, em especial as regras sobre o consentimento presumido, artigo 34.. do Código Penal e artigos $134 . .0$ e $135 . .^{\circ}$ do Código Penal a respeito o crime de homicídio a pedido da vítima e auxílio ao suicídio.

De acordo com o artigo 1.. , n.ำ da Lei n.. $25 / 2012$, estaremos perante uma directiva antecipada quando o outorgante, maior de idade e com plena capacidade de agir, manifesta a sua vontade, através de documento autêntico, quanto à determinação dos cuidados de saúde que deseja ou não receber, caso se venha a encontrar incapaz de consentir. Trata-se da expressão de uma vontade prospectiva conducente a assegurar a autodeterminação dos seus interesses no que à sua esfera pessoal da saúde e integridade física diz respeito quando deixa de se encontrar numa situação de decisão em sede de responsabilidade própria.

\footnotetext{
2 Projecto de Lei $n .^{\circ}$ 788/X, disponível no sítio www.parlamento.pt/ActividadeParlamentar.

3 Parecer n. ${ }^{\circ}$ 57/CNECV/09, disponível no sítio www.cnecv.pt.
} 
Distinto da autonomia prospectiva serão as situações em o paciente presta o seu consentimento em momento prévio à intervenção, vindo a ocorrer ulteriormente uma situação de incapacidade. Nestes casos a manifestação de vontade do paciente é de consentimento actual, mantendo-se a eficácia autorizativa enquanto a intervenção e respectivo objecto integrarem o âmbito do consentimento inicialmente prestado. Se alguém consente uma cirurgia recusando, de forma livre e esclarecida, que, em caso de complicações receba, por exemplo, uma transfusão de sangue, tal constitui a manifestação de uma decisão vinculativa não sujeita ao regime das directivas antecipadas, e cuja violação do dever de omissão qualifica a conduta do médico como crime de tratamento médico arbitrário.

O que caracteriza a directiva é que na sua génese a manifestação da vontade não é eficaz e vinculativa enquanto o outorgante for plenamente capaz para consentir a intervenção médica. Podendo inclusive o consentimento prestado em determinado momento ser bastante para revogar ou modificar a própria directiva, na medida em que a forma legal apenas é exigida para a outorga da directiva.

As directivas são assim um instrumento de exercício do direito à autodeterminação, e desta forma não deixarão de integrar o instituto do consentimento, verdadeira expressão da autonomia da vontade e limitação (antes verdadeiro exercício) dos direitos de personalidade, previstos nomeadamente o artigo 81. do Código Civil. O consentimento é uma expressão do próprio direito que se limita e que resulta da liberdade ética de uma pessoa.

Ora, o consentimento, em termos gerais, corresponde a uma declaração de vontade que visa uma determinada consequência jurídico-prática: conformação da sua personalidade e da correspondente tutela legal (1). Através do consentimento, a pessoa permite ou autoriza a intervenção por um terceiro na sua esfera jurídica: volenti non fit injura. De acordo com Vaz Serra, através do consentimento o lesado torna-se "partícipe da causa do dano, apropriando-se, «por assim dizer», dela renunciando à tutela jurídica, de sorte que a causa do dano não é estranha ao sujeito" (2). Todavia, mais do que participante, o lesado é o verdadeiro decisor da conduta de terceiro na medida em que dele depende o fundamento e a justificação daquela. Podemos dizer que o comportamento do terceiro resulta de um acto complexo. Como tal, o consentimento terá sempre de ser prévio ou contemporâneo da lesão. Se for em sede posterior, já estaremos perante um 
problema de renúncia às garantias legais resultantes da actuação ilícita, na medida em que não é possível lançar mão da justificação a posteriori. O consentimento qua tale corresponde a uma conduta social típica, e por isso conforme a ordem jurídica, que justifica a actuação de terceiro, qualificando-a como lícita (3).

Resulta, a nosso ver, que as directivas antecipadas se hão-de qualificar como verdadeiro consentimento e que se tratam de um simples acto jurídico, pessoal de natureza formal manifestado através de uma vontade expressa, que por força e relevância da vontade integra a categoria de quase negócios jurídicos, regulado pelo artigo 295. do Código Civil. Isto porque os seus efeitos resultam ex lege, não relevando autonomamente a vontade quanto à produção dos mesmos.

O outorgante apenas se pode pronunciar prospectivamente sobre o que entende ser para si o âmbito dos cuidados médicos que autoriza ou recusa, conforme a sua vontade hipotética e escala de valores e interesses sobre um determinado evento futuro, que poderá certo ou incerto, quer no acontecimento, quer no momento. Pode por isso ser um evento próximo, remoto, provável, improvável, inverosímil. Este hiato temporal traz consigo o risco da actualidade da vontade então manifestada e assim da sua força vinculativa. Ciente desta especificidade o legislador estabeleceu prazos de caducidade da eficácia das directivas de 5 anos.

No entanto, nem o prazo de cinco anos é garante de uma plena vinculatividade, nem a caducidade da directiva dita a sua total e absoluta ineficácia. Sendo obrigação do médico, antes da intervenção, a obtenção de um consentimento actual, este terá que aferir da actualidade da directiva ou, na ausência desta, de reconstruir a vontade presumida do paciente. Isto significa que, apesar da caducidade da directiva, esta não deixará de ser um repositório dos interesses e vontade do outorgante essencial à construção da escala de valores e interesses para uma decisão de um terceiro sobre a esfera pessoal do outorgante. Quer seja o médico ao abrigo do consentimento presumido, quer seja o representante legal.

Outra nota sobre a vinculatividade da vontade prospectiva resulta da condição de dupla actualidade da mesma, face a um concreto processo de decisão médica. Dizemos dupla actualidade quer quanto à validação da vontade prospectiva junto da vontade presumida, quer em termos do grau de informação e esclarecimento face à evolução da ciência médica (esta evolução pode determinar a desactualidade da vontade prospectiva). 
No momento em que a directiva releva, os seus efeitos resultam da lei e não exclusivamente da vontade. O outorgante apenas manifesta a vontade em aderir ou não a uma determinada terapêutica para estritos efeitos de manifestação do consentimento ou dissentimento necessário para a realização de uma intervenção nos bens jurídicos vida e integridade pessoal.

As dificuldades podem, no entanto, surgir no que toca à delimitação do que é exercício lícito da autodeterminação, ou seja quais sãos os limites da ordem pública e se a consagração legal permitir legalizar e reconhecer o direito à eutanásia. Demonstrativo disso mesmo é verificar que actual lei foi aprovada por partidos da dita direita conservadora e esquerda radical, não existindo qualquer oposição de fundo ao carácter

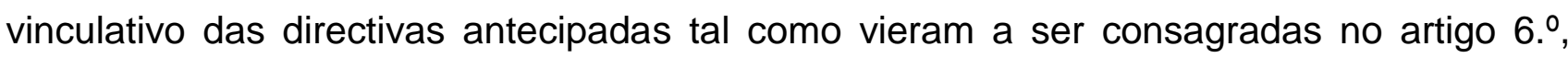
mesmo que o cumprimento dessas signifique a não realização de um tratamento que seria adequado a evitar a morte do paciente. Daí estar expressamente previsto que podem integrar o objecto das directivas a possibilidade de se recusar alimentação e hidratação artificiais ou ainda a recusa ou suspensão de cuidados médicos necessários para evitar a

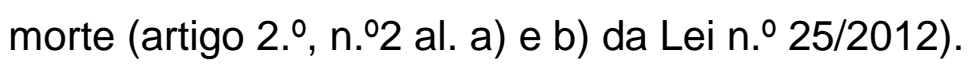

Outra nota importante é que a lei surge descontextualizada, na medida em que não integra expressamente o ramo de direito penal ou direito civil, surgindo como lei avulsa e sem promover a alteração de qualquer disposição penal ou civil. Partindo da relação jurídica que a lei pretende regulamentar, o direito à autodeterminação prospectiva e concretização do dever especial (em regra será omissivo, mas poderá ser positivo) que incide sobre o responsável pelo cuidado de saúde, é nosso entendimento que se trata do enquadramento do exercício deste direito e respectivas garantias no âmbito do direito de personalidade. Direito este que pela sua natureza e eficácia absoluta se impõe quer no âmbito de uma relação contratual de prestação de serviços (típica relação de direito privado e contratual) ou no âmbito do acesso a cuidados de saúde prestados pelo Serviço Nacional de Saúde (típica relação de direito público; todavia, pela natureza de direito de personalidade, os deveres impostos aos profissionais de saúde não deixam, não obstante o especial regime de responsabilidade extra-contratual, de se reportar ao âmbito privado). Por isso, mais do que a questão da relação jurídica subjacente aos cuidados de saúde, o objecto afectado por um cuidado médico é de natureza privatística integrante de uma 
relação jurídica emergente de um direito de personalidade (artigo 70., n..1 do Código Civil).

A natureza privada das directivas antecipadas é relevante para configurar o poder que é reconhecido ao outorgante de uma directiva antecipada enquanto afirmação da sua personalidade e capacidade, no fundo, a concretização e exercício da sua liberdade de planeamento e definição dos seus interesses em virtude de uma possível ou hipotética incapacidade. As directivas antecipadas resultam do exercício individual e privado do outorgante na conformação da sua esfera pessoal de interesses apenas limitado pela ordem pública (artigo 81.ํ, n.ำ do Código Civil e 5.ำ a) da Lei n.ำ 25/2012, e já não os bons costumes nos termos do artigo 340.- n. n. 2 do Código Civil).

Até porque a questão dos cuidados de saúde integra 0 interesse de autodeterminação do titular sendo este igualmente o bem jurídico tutelado criminalmente, na medida em que o acto médico não autorizado, logo arbitrário, é punido criminalmente (artigo 150. CP). Partindo de uma concepção de unidade da ilicitude assente no princípio da harmonia material, ou seja, na inexistência de incongruências ou antinomias na protecção de interesses jurídicos, podemos dizer que há um alinhamento sobre o que integra o conceito de ordem pública na hora de determinar os limites do consentimento.

A actuação do médico, quando conforme a legis artis, apenas é punível quando não seja autorizada pelo paciente. Ou seja, os interesses a tutelar, devido à dignidade do acto médico, serão sempre a autodeterminação do paciente, porquanto o acto médico per se é insusceptível de qualquer censura ou desvalor jurídico uma vez que é qualificado como conduta atípica para efeitos dos bens jurídicos vida ou integridade física. Assim vale para a tutela da esfera pessoal do paciente, onde o interesse será sempre a autodeterminação ao

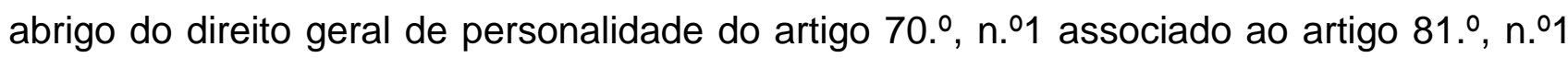
do Código Civil.

Daqui resulta claro que, para ordem jurídica portuguesa, a autodeterminação do paciente é que pode fazer resvalar para a ilicitude uma intervenção, mesmo que no interesse objectivo daquele e conforme as legis artis. Citando Faria Costa "o acto médico só existe se o paciente quiser que exista" (4). Esta conclusão, serve de premissa para a construção do conceito de ordem pública portuguesa e os limites da autodeterminação do paciente e que serão comuns quer ao direito privado, quer ao direito público. 
O conceito de ordem pública resulta daquelas normas e princípios jurídicos absolutamente imperativos que formam os quadros fundamentais do sistema, sobre eles se alicerçando a ordem económico-social, pelo que seriam interrogáveis pela vontade dos indivíduos. Segundo Malaurie (apud Baptista), "ordem pública se consubstancia no «bom funcionamento das instituições indispensáveis à colectividade»" (5). Baptista Machado diz ainda que a ordem pública "coordena e limita os institutos e princípios basilares do sistema jurídico, em ordem a garantir a subsistência de cada um, só possível dentro do equilíbrio do todo. Representa, por assim dizer, o sector-piloto do sistema" (5) (6).

Contudo, em sentido próprio, mais do que falar em ordem pública, o que está em causa, como vimos, é a concordância sistémica entre valores e bens jurídicos que conformam a personalidade jurídica, isto porque a verdadeira manifestação de autonomia responsável no âmbito dos cuidados médicos, pressupõe a assunção da responsabilidade própria por uma tomada de decisão e suas consequências que afectam a essencialidade humana (quer seja a vida, integridade física, autonomia ou liberdade religiosa). Dentro deste quadro, qualquer decisão livre e esclarecida que possa implicar — aqui entendida como decisão que recusa (quer para dar início, suspensão ou cessação) uma intervenção necessária e adequada a evitar a morte ou a afastar o perigo de morte - a morte terá que ser aceite se for expressão inequívoca da liberdade de aceitar ou não a intervenção de terceiros mesmo que com fins benéficos para a pessoa. Bem como qualquer decisão que, ainda que escape aos critérios de razoabilidade e racionalidade, resulte de uma vontade séria, expressa, livre e esclarecida. O projecto de vida é de escolha individual e livre, pelo que é soberania do eu sobre o devir e, neste sentido, aceitar o processo natural tendente ao fim da vida. Aliás, encontra-se consagrado no artigo $41 . \stackrel{\circ}{n}, . .1$ da Constituição a liberdade de consciência, pelo que as decisões tomadas de forma livre e esclarecida, devem ser respeitadas independente do grau de censura ético, religioso ou social que se possa fazer, quer na óptica do médico, quer no pretenso entendimento global de valores. As motivações de ordem religiosa, concepção do mundo, da vida e de morte de terceiros são por isso, como nota Figueiredo Dias, irrelevantes (7).

A autodeterminação assim entendida não vai contra a ordem pública, muito pelo contrário, impõe-se através daquela, não podendo o titular do direito ficar sujeito a decisões tomadas por terceiros em nome de um pretenso interesse jurídico autónomo e separável da personalidade. O interesse vida não tem um valor autónomo e exogéneo à 
soberania do paciente sobre a sua esfera pessoal. É da essência e dignidade humana que as intervenções, por mais benévolas e bem-intencionadas que pretendam ser ou necessárias à salvaguarda da vida do paciente, dependam da autorização do beneficiário das mesmas.

A dialéctica que se possa estabelecer entre autodeterminação e vida pressupõe a resolução estrutural da conformação da esfera de personalidade, sendo que o resultado da tensão terá que partir da preservação da dignidade da pessoa e da sua autodeterminação, de modo responsável, para traçar a sua vida. Isto pressupõe que os limites do consentimento, quer seja prospectivo, quer ser contemporâneo, são os mesmos, apenas diferindo na certeza de que a vontade então manifestada corresponde à vontade actual.

Aliás a relevância da vontade é tal que, mesmo nos casos em que ela viola a ordem pública e por isso é ineficaz, não deixa de relevar para efeitos de privilegiar a conduta de alguém que mata outra pessoa a pedido da vítima (falamos aqui da eutanásia, art. 134. do Código Penal). A construção deste tipo legal decorre da concordância prática entre a relevância do interesse autodeterminação da vítima que quis e deu a sua aquiescência quanto ao resultado, e a tutela do interesse jurídico superior que é a vida (artigo 24.. , n.. 1 da Constituição: a vida humana é inviolável) justificou a natureza privilegiada e respectiva moldura penal abstracta máxima de pena de prisão até 3 anos (moldura que admite 0 pleno funcionamento do princípio da diversão em matéria de fixação das penas). Isto porque o homicídio a pedido da vítima pressupõe uma dimensão de heterolesão a par da autolesão (8).

Os limites da autodeterminação, no caso das directivas antecipadas, prendem-se com a afirmação da personalidade individual, pelo que o direito à vida resulta enquanto direito objectivo tutelado pela ordem jurídica, na medida em que tal vida seja querida por decisão do seu titular. A relevância jurídica e comunitária do cuidado médico aliado à preservação dos bens jurídicas vida e integridade física não poderá, nunca, ultrapassar a autodeterminação do titular individual daqueles bens, nem tornar o fim da preservação da vida humana biológica com um fim em si mesmo.

Serão estes limites que determinam o objecto da directiva e consequentemente 0 direito à autodeterminação. Por isso este apenas vale para as situações em que o outorgante seja soberano sobre o domínio da decisão da intervenção médica, ou seja, apenas será eficaz quanto consentimento e dissentimento dos actos médicos indicados. 


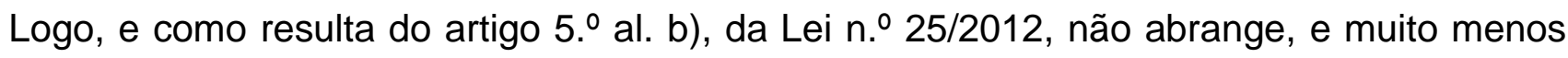
reconhece, o direito a morrer. No fundo, só existe poder de decidir sobre o que está no domínio de decisão, e este tem somente como objecto autorizar ou não uma intromissão na nossa esfera pessoal, que pode evitar ou retardar um fim, de per si involuntário: a morte. De certa forma, ainda que se reservem as devidas adaptações, o processo de decisão, presente ou antecipada, do paciente pressupõe que até à sua decisão se encontre na posição do gato de Schrödinger. Até à decisão final é possível existirem dois universos paralelos, cujo critério decisório relevante é a vontade do outorgante. Aliás, o não reconhecimento de um direito à morte alinha-se com o artigo 2.ㅇ da CEDH e respectiva interpretação sancionada pelo Tribunal Europeu dos Direitos do Homem, como sucedeu no caso Pretty v. The United Kingdom. Neste, o tribunal esclareceu que o artigo 2.. $d a$ convenção não pode, sem que se incorra numa distorção da sua letra, ser interpretado como consagrando um direito diametralmente oposto ao direito à vida, nomeadamente 0 direito à morte; nem confere o direito de auto-determinação à pessoa de escolher a morte face à vida. Esta posição do Tribunal Europeu dos Direitos do Homem alinha-se, aliás, com a Recomendação (CE) 1418 (1999).

O paciente é soberano de si e do seu corpo, pelo que pode recusar qualquer tratamento médico, independentemente da bondade ou necessidade do mesmo e, decisivo, independentemente da não realização do acto médico indicado ter como consequência a sua morte. Tal não é contrário à ordem pública. Apenas se impõe que a pessoa seja plenamente capaz de decidir, seja presencial ou no momento da outorga da directiva antecipada.

No entanto fica por determinar o que se pode entender por decisão que implique deliberadamente a morte não natural e evitável (aqui se inclui a eutanásia e a ajuda ao suicídio, artigos 134. e 135. do Código Penal, respectivamente). Determinação tão mais necessária quando é esta que baliza os limites da ordem pública. A ideia de morte não natural ou evitável surge por oposição à morte enquanto consequência, não da recusa de consentimento (dissentimento), mas como desfecho do fenómeno natural e biológico da vida. Aliás, o cuidado médico apresenta-se como causa ou possível causa da interrupção do processo natural tendente à morte. Quando o mesmo não seja proporcional a este fim, o acto médico deixa de ser conforme a legis artis, sendo ele próprio violador da dignidade do paciente e deste modo ele próprio violador da ordem pública (artigo 2.ํ, n.․ำ al. b) 
alinhado com o artigo 5.- al. a) da Lei $n .^{-}$25/2012). A lei fala de tratamento fútil, inútil ou desproporcionado no seu quadro clínico e de acordo com as boas práticas profissionais.

Em termos técnicos um tratamento fútil não preenche o requisito da necessidade, logo da indicação médica, pelo que a sua realização é qualificada como uma ofensa à integridade física. De forma mais extrema, a obstinação terapêutica ou escarnecimento terapêutico seria uma forma de má prática médica com vista ao prolongamento da vida a todo o custo e com a consequente ofensa à integridade física e subsequente instrumentalização da pessoa na salvaguarda de um interesse jurídico a montante do doente.

Contudo as linhas claras traçadas a regra e esquadro pelo legislador português não são capazes de eliminar as sombras com que o traço grosso legal pretende separar. Em especial na concretização do que é um processo natural e irreversível de morte. Ficamos assim na sombra de um processo de decisão, que depende da interpretação da directiva antecipada nas suas múltiplas dimensões: sentido da vontade real e actualizada da directiva (i), adequação do seu objecto face à intervenção médica em causa (ii), eficácia da mesma (iii).

Ou seja, que conduta é exigível ao médico perante uma directiva antecipada que recusa $o$ acto medicamente indicado, em especial quando o respeito pela mesma tem como resultado imediato a morte?

Numa visita a uma unidade de medicina intensiva em Portugal constatamos que a linha entre a vida e a morte se discute em sede colegial de médicos, em zona restrita e numa linguagem médica: as decisões de descontinuação terapêutica. No entanto, assim nos pareceu, o processo de decisão era reservado aos médicos e perante considerações de ciência médica, sem dar qualquer relevância directa à esfera de interesses subjectivos do paciente. Neste processo discute-se a proporcionalidade do início, manutenção ou cessação do tratamento médico tendo em conta o respeito pela dignidade do paciente. Isto porque, jurídica e eticamente, não existem diferenças entre iniciar, suspender ou cessar um tratamento médico. Em último termo, e no que aos meios de suporte artificial de vida diz respeito, a manutenção artificial da vida, quer ab initio, quer durante, equivalem-se porquanto se trata da "adequação do esforço terapêutico às reais necessidades do doente" (9). 
Em última instância podemos mesmo dizer que o resta e corporiza o Homem enquanto fim em si mesmo é o respeito pela sua dignidade. A dignidade da pessoa humana é erigida como princípio basilar e limite do Estado de Direito Democrático. O artigo $1 .^{\circ}$ da Constituição estatui, de forma expressa, que "Portugal é uma República soberana, baseada na dignidade da pessoa humana". O poder do Estado assenta, assim, na pessoa humana, consagrando, simultaneamente, a pessoa como fim em si mesmo - a dignidade da pessoa humana é um prius (10) (11) (12) (13) (14) - e afirmando a dignidade como um verdadeiro axioma de toda a ordem jurídica. A toda e qualquer pessoa se reconhece a sua personalidade ilimitável enquanto tal, o que, segundo Orlando Carvalho, resulta numa "ilimitabilidade das prerrogativas jurídicas que se ligam ao simples facto de cada homem ser homem" (15). A vida é um dos pressupostos dessa dignidade, mas não é o fim desta, tanto mais que somos, sem que pretendamos resvalar para uma concepção niilista, seres para a morte.

A dimensão qualitativa e abstracta da dignidade da pessoa humana implica um tratamento igualitário, independentemente da ausência de competência para o sujeito se autodeterminar e agir. É, em nosso entender, a dimensão de igualdade material que impõe o respeito por uma vontade antecipada com valor e força equivalente a uma vontade presente. Comum às duas é sempre a existência de uma vontade livre, informada e actual, pelo que o momento em que ela é manifestada só releva em termos de certeza e segurança da vontade real. Isto porque ambas correspondem à manifestação de uma vontade real.

Em uma perspectiva jurídica, os limites de ordem pública da autodeterminação prospectiva resvalam para a determinação da causalidade do resultado morte. Ou seja, a intervenção (ou melhor, omissão) do médico não pode ser determinantes para o resultado morte, na medida em que a omissão ou interrupção de um tratamento, apesar de ser a causa de encurtamento do tempo de vida, este, bem como o resultado morte, não são objectivamente imputáveis àquela omissão (16).

Isto porque o respeito pela vontade real, quer resulte de forma directa, quer por via de uma directiva antecipada, impõe um dever de respeito pela vontade do paciente, não sendo qualificado como crime a omissão ou interrupção de tratamento (16). Voltando à imagética do paciente estar na posição do gato de Schrödinger, podemos dizer que o que distingue a omissão do tratamento médico do homicídio é que neste último é determinante 
o facto de nunca existir a possibilidade de escolher entre a vida e a morte, ou seja, não existe alternativa. A morte resulta da decisão e não de um processo causal natural. A morte tem como causa a intervenção humana, quer por acção, quer por omissão. Distintamente, a descontinuação terapêutica, quer seja por critério clínicos, quer seja por vontade do paciente, pressupõe que a até à sua tomada de decisão, seja possível ao paciente a vida ou a morte. Há por isso uma relação de sobreposição quanto ao resultado e consequente direito à liberdade de escolha.

Deste modo, uma vez esclarecidos os limites das directivas antecipadas, a consequência natural do desrespeito das mesmas será a tutela civil e penal a luz do regime dos tratamentos médicos arbitrários. Ainda que o tratamento salve a vida do paciente, não deixará de ser ilícito, quer civil, quer criminal. Em especial quando o dever de respeito da vontade do paciente prevalece sobre o dever de acção do médico. Demonstrativo disto mesmo e das garantias da consciência do médico, prevê o artigo 9.ำ da Lei n.ำ 25/2012 a faculdade de objecção de consciência.

A directiva antecipada de vontade pode ter como objecto a manifestação de uma vontade expressa quanto aos cuidados de saúde que o outorgante deseja receber, ou não deseja receber, no caso de, por qualquer razão, não ser capaz de decidir autonomamente

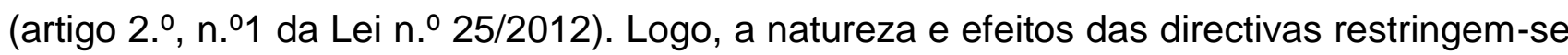
ao âmbito dos cuidados médicos e têm em vista constituir uma forma de suprimento privado da incapacidade para prestar consentimento. Ou seja, as directivas permitem que alguém que hoje é incapaz de decidir, possa em momento prévio determinar, se autoriza ou não determinado tratamento ou que tipo de tratamentos quer ou não quer. O objecto destas directivas pode por isso ser de conteúdo amplo, ainda que limitado ao âmbito dos cuidados médicos. Aqui o termo cuidado médico é mais amplo que acto médico, pelo que se incluem todos os tratamentos e cuidados básicos associados a um tratamento médico, nomeadamente a chamada nutrição e hidratação artificiais (17), (18).

Qualquer directiva em que se afirme a vontade de beneficiar de qualquer acto médico só será válida e eficaz, para efeitos da Lei n. 25/2012, na medida em que não seja contrária a indicação médica, por extravasar o objecto legal e respectivo âmbito legal de protecção da autonomia prospectiva consagrado na lei. O direito de autodeterminação está por isso limitado intrinsecamente ao poder de decisão autónomo que se restringe a consentir ou dissentir determinado acto médico, pelo só dentro do espartilho dos actos 
medicamente indicados é que o outorgante pode manifestar uma vontade positiva vinculativa.

Existindo um directiva antecipada válida e eficaz nos termos da lei, o médico tem o dever de respeitar essa mesma vontade (artigo 6.․, n.ำ da Lei n. 25/2012). Resulta daquela a manifestação de um consentimento prospectivo que tende a exercer na plenitude o direito de autodeterminação, ou seja, decidir em sede de responsabilidade própria. Isto significa que o médico está obrigado, por força do dever legal prescrito no

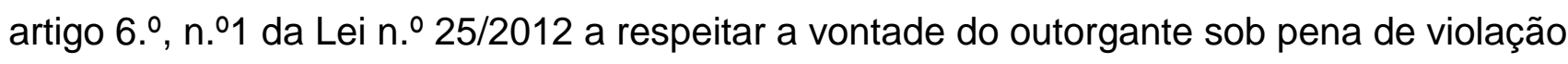
do direito de autodeterminação e do dispositivo legal, resultando daquela uma actuação ilícita susceptível de gerar a obrigação de indemnização - artigo 483.․․, n.ํ1 do Código Civil.

A afirmação da autodeterminação deve prevalecer, se assim resultar de uma vontade livre, esclarecida e actual, mesmo que a decisão implique a morte natural evitável ou cujo perigo seria removido ou diminuído caso se interviesse de acordo com a indicação médica, não colocando em causa a dignidade da pessoa humana, logo não colocando em causa a eficácia da declaração de vontade. Isto significa que resulta da lei a consagração da autodeterminação prospectiva, mesmo que tal implica o resultado morte, assim resulta do artigo 2.. , n.-2 al. a) da Lei n. $-25 / 2012$. Valem por isso, com toda a pertinência, os limites do direito de autodeterminação em confronto com os interesses vida e integridade física conforme é reconhecido no direito penal e na tutela dos bens jurídicos penais. O grau de vinculação irá sempre depender das consequências que acarreta o respeito pela vontade prospectiva e das exigências de uma vontade clara e esclarecida expressa no documento.

Daí que, reportando-nos ao problema da interpretação do documento e da vontade consciente e esclarecida exigida no artigo 2.. , n..1 da Lei n.. 25/2012, tenhamos, mais do que assegurar que as directivas são uma biografia na e para a doença, determinar qual é a vontade real do outorgante e se a mesma se mantém, e qual o destino que este quis e quererá para si mesmo. Pugnamos por isso, face ao documento que constitui a directiva antecipada, por uma interpretação subjectivista cujo resultado, num primeiro momento, deve ser estritamente declarativo. No entanto, não basta o resultado declarativo, pois é dever do médico obter um consentimento actual, o que pressupõe um segundo momento interpretativo de natureza teleológica e com vista à qualificação do acto médico em concreto e a vontade manifestada. Dentro deste quadro metodológico, e por efeito prima 
facie, será sempre lícita a actuação do médico, pois actuou de acordo com uma vontade justificante. Ilidida que seja a presunção sobre o sentido da vontade real do outorgante, e sendo esta desconhecida do médico, quando devidamente justificado pelas circunstâncias concretas ao ponto de torna inexigível conhecer da vontade real do outorgante constitui causa de exclusão de culpa do médico caso a intervenção deste seja contra a vontade e consentimento prestado e cujo resultado mais do que dirigido a um hipotético ou eventual acto médico, diz respeito à vida que o outorgante pretende levar. A consequência prática da exclusão da culpa é de não fazer nascer na esfera jurídica do médico qualquer obrigação de indemnização; contudo, os interessados poderão sempre reagir nos termos

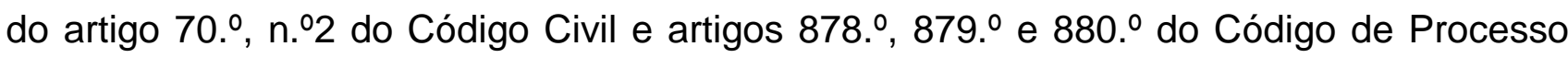
Civil, pois a actuação médico é ilícita.

Salvo, claro está, se a directiva padece de algum dos vícios previstos no artigo $5 .^{\circ}$ da Lei n. - 25/2012 e fosse exigível ao médico conhecer dos mesmos. Concluindo, o resultado interpretativo que se obtenha terá que ser depois necessariamente confrontado com o tratamento e procedimentos médicos que careçam de consentimento, com vista a retirar do sentido do texto o seu âmbito de eficácia de acordo com o seu objecto. Por isso, a actuação do médico na busca do sentido e vontade actual, face à vontade prospectiva, exige que este teste a actualidade da directiva e que o objecto desta seja conforme a realidade da situação concreta. Se cumprido este iter, não pode ser exigível ao médico qualquer outro comportamento distinto, pelo que actua sem culpa (artigo 487.. , n.. 2 do Código Civil).

A grande finalidade (assim interpretamos) da Lei n.․ 25/2012 é impor um dever jurídico, de fonte legal, ao médico de respeitar o consentimento prospectivo do outorgante contra a indicação médica imposto pelo caso. Qualifica-se assim como norma de protecção da manifestação de autonomia prospectiva para prestação de consentimento para actos médicos. A lei surge como forma de reconhecer juridicamente efeitos vinculativos à vontade prospectiva do outorgante retirando da conduta do médico, em conformidade com a vontade expressa, qualquer ilicitude por actuar ou não actuar de acordo com o medicamente indicado. O comportamento do médico é por isso parte integrante do exercício do direito de autodeterminação prospectivo do outorgante, não constituindo qualquer ilícito. Se é verdade que as directivas têm como função servir de instrumento da realização da autodeterminação do paciente, esta nova figura jurídica desempenha uma 
função de salvaguarda dos médicos encarregados do tratamento, bem como dos restantes profissionais de saúde envolvidos. E, ainda, de certa forma exime a família ou pessoas chegadas de decisões difíceis. A ideia que perpassa (e que acolheu respaldo na solução legal) é dar certeza quanto à vontade presumida do paciente, pois o médico continua a ter o dever de assegurar a actualidade de tal vontade então manifestada. Isto significa que o médico pode-se valer do efeito prima facie que resulta da directiva, mas tal não afasta a sua eventual responsabilidade.

\section{Referências}

1. Ribeiro, G . A protecção do Incapaz Adulto no Direito Português, Coimbra: Coimbra Editora, 2010.

2. Vaz Serra, APS. Causas Justificativas do Facto Danoso. Boletim do Ministério da Justiça, n. $95,1959$.

3. Larenz,K. Lehrbuch des Schuldrechts. 13. Auflage. Montagem por Claus-Wilhelm Canaris. Vol. Band 2. München: Beck, 1994.

4. Faria Costa, J. Em Redor Da Noção De Acto Médico. In As Novas Questões Em Torno Da Vida E Da Morte Em Direito Penal. Uma Perspectiva Integrada. Coimbra: Coimbra Editora, 2010.

5. Baptista, J. Lições de Direito Internacional Privado. 3." edição. Coimbra: Almedina, 1999.

6. Silva Vaz, AP. Objecto da obrigação - a prestação - as suas espécies, conteúdo e requisitos. Boletim do Ministério da Justiça, n. 74, 1958.

7. Figueiredo Dias, J. A "Ajuda À Morte: uma Consideração Jurídico-Penal. Revista de Legislação e Jurisprudência 137, no. 3949 , 2008.

8. Costa Andrade, M. Anotação Ao Artigo 134. (Homicídio a Pedido Da Vítima. In Comentário Conimbricense do Código Penal. Parte Especial . Coimbra: Coimbra Editora, 1999.

9. Nunes, R Guidelines Sobre a Suspensão e Abstenção de Tratamento em Doentes Terminais. Serviço de Bioética e Ética Médica (FMUP), 2008.

10. Canotilho JJG e Moreira, V. Constituição da República Portuguesa Anotada, 4. a edição revista. Coimbra: Coimbra Editora, 2007. 
11. Miranda J e Medeiros,R. Constituição Portuguesa Anotada, Tomo I .Coimbra: Coimbra Editora, 2005.

12. Carvalho, O Teoria Geral do Direito Civil Coimbra: Centelha, 1981

13. Sousa, RC. O direito geral de personalidade Coimbra: Coimbra Editora, 1995.

14. Barbosa de Melo, Democracia e Utopia (reflexões) Porto, 1980

15. Carvalho, O. Os direitos do Homem no Direito Civil . Coimbra: Vértice, 1973

16. Figueiredo Dias, J. A Ajuda à Morte": uma Consideração Jurídico-Penal. Revista de Legislação e Jurisprudência 137, no. 3949 ,2008.

17. McCullagh, P. Conscious in a vegetative state? A Critique of PVS Concept. DordrechtBoston-London: Kluwer Academic Publishers, 2004.

18. Faria Costa, J Em Redor da Noção de Acto Médico. In As Novas Questões em Torno da Vida e da Morte em Direito Penal. Uma Perspectiva Integrada Coimbra: Coimbra Editora, 2010.

Recebido em: 19/9/2016

Aprovado em: 29/9/2016

\section{Como citar este artigo:}

Ribeiro GR. Fim de vida e recusa de tratamento médico no direito Português. Revista Cadernos IberoAmericanos de Direito Sanitário. 2016 jul./set, 5(3):119-134. 